\title{
DESIGNING A CURRICULUM FOR CREATIVITY
}

\author{
Emma Webster*
}

\section{INTRODUCTION}

Creativity is a field that gained significant research momentum after Guilford's Creativity in 1950 (Guilford, 1950). ${ }^{1}$ It is an area relevant to the arts, most obviously, psychology, technology, science, business, education; in fact, the list of fields where it holds no relevance would perhaps be a lot shorter, albeit far more challenging to put together. The field has historically been associated with divergent thinking and intelligence, but is now seen as an attribute applicable to all and of great value to the economy, innovation and well-being.

The nurture and development of creativity is of particular interest in the field of education and forms the focus of a great deal of significant reports and writings, including the Durham Commission (2019). ${ }^{2}$ Ofsted are also keeping pace with their new inspection framework referring to 'culture capital' within the evaluation of a school's curriculum intent (Ofsted, 2019). ${ }^{3}$ Creativity within curriculum design is essential in finding ways to make education relevant and appropriate. The curriculum should be designed in a creative way, to integrate creative approaches and nurture creativity in students, and also teachers. Creativity is enriching to all elements and at all stages of life, and education should be leading the way in raising its profile.

\section{CREATIVITY}

Defining creativity is an area of research that has been on a significant journey since Guilford's address in the 1950s. More recent definitions highlight the importance for innovation in creativity, as well as the need for value and purpose. Robinson $(2010)^{4}$ defined creativity as 'original ideas that have value' and Csikszentmihalyi $(1996)^{5}$ makes the connection with creativity and happiness. The

\footnotetext{
* Emma Webster BA(Hons), MA, PGCE, NPQML

1 Guilford, J. P. (1950) 'Creativity', American Psychologist. doi: 10.1037/h0063487.

2 Newton, L. D., 2019. Durham commission on creativity in education.

3 Ofsted (2019) Education inspection framework for September 2019, The Office for Standards in Education, Children's Services and Skill.

${ }^{4}$ Robinson, K. (2007) 'Sir Ken Robinson: Do schools kill creativity?', Ted Talks.

5 Csíkszentmihályi, M. (1996) Flow and the psychology of discovery and invention, New York: Harper Collins. doi: 10.1037/e586602011-001.
} 
recent Durham Commission report (2019) identifies creativity as 'the capacity to imagine, conceive, express, or make something that was not there before'; similarly, the Arts Council, in their new 10 year strategy (2020), ${ }^{6}$ identify creativity as 'the process through which people apply their knowledge, skill and intuition ... to make something that was not there before'. Creativity, and the nurture of it, sits well within the progression of the curriculum and, as Bröckling $(2006)^{7}$ explained, 'is tied to the human potential to bring into being something new'.

In defining creativity, we must consider the nature of conflicting ideas that it embodies. There are a number of significant dichotomies that promote discussion and debate in the field of creativity; domain-specific and domain-general creativity, divergent and convergent thinking, and individual versus group creativity, to name a few. Wallace $(1986)^{8}$ discusses the ability for creativity to reconcile conflicts, which makes these oppositions all the more interesting, as they can find synthesis within their very topic.

Baer (2012) ${ }^{9}$ contemplated this ability for creativity to resolve conflict in his questioning of creativity being domain-specific. He notes a lack of clear definition of the term 'domain' in the first instance, supported by Sternberg (2015),${ }^{10}$ and the fact that the debate remains subjective throughout. Domain-specific creativity utilises the difference between little-c and Big-C creators to define itself. Big-C creators show significant culture and domain changing creative abilities, that are often attributed to just one field. However, those achieving a more everyday level of creativity, little-c, have the ability to be somewhat creative in a range of activities: domain-general creativity. Kaufman and Beghetto (2009) ${ }^{11}$ extended the little-c and Big-C categories to include mini-c and Pro-c levels, to encompass an even broader range of creative abilities and achievements. This is another important model when considering the advice for improved creativity nurture in primary schools.

\footnotetext{
${ }^{6}$ Arts Council England (2020) 'Let's create'.

7 Bröckling, U. (2006) 'On creativity: A brainstorming session', Educational Philosophy and Theory. doi: 10.1111/j.1469-5812.2006.00208.x.

${ }^{8}$ Wallace, B. (1986) 'Creativity: Some Definitions: the Creative Personality; The Creative Process; the Creative Classroom', Gifted Education International. doi: 10.1177/ 026142948600400202.

${ }^{9}$ Baer, J. (2012) 'Is Creativity Domain Specific?', in The Cambridge Handbook of Creativity. doi: 10.1017/cbo9780511763205.021.

${ }^{10}$ Sternberg, R. J. (2015) 'Teaching for creativity: The sounds of silence', Psychology of Aesthetics, Creativity, and the Arts. doi: 10.1037/aca0000007.

${ }^{11}$ Kaufman, J. C. and Beghetto, R. A. (2009) 'Beyond Big and Little: The Four C Model of Creativity', Review of General Psychology. doi: 10.1037/a0013688.
} 
The debate between divergent and convergent skills began with Guilford's proposal that there are two ways of thinking, and that divergent thinking, encouraging the generation of multiple ideas rather than just one, was the centre of creativity (Guilford, 1950). Divergent thinking is an important element to consider when attempting to define creativity because, even though it is not synonymous, it plays a significant role. Robinson $(2010)^{12}$ refers to the research of Land and Jarman (1993) ${ }^{13}$ that assesses the divergent thinking ability of children tested at various ages. The results demonstrate that 5-6-yearolds have a higher percentage (98\%) of genius-level results, and this is interpreted by Robinson to show that we all have the potential to be geniuslevel divergent thinkers, and ultimately effective creative beings. The problem is education and what it removes from our nature approach to learning. By eliminating creative opportunities in the curriculum and replacing them with a 'one-size-fits-all' experiences of education, we are taking away the potential of generations.

Guilford recognised the process of creativity and identified four stages preparation, incubation, illumination and verification - which formed an initial model of creativity that has inspired many alternative versions since. These models, from Rhodes' '4Cs' (1961) ${ }^{14}$ to Runco's '6Ps' (2007) ${ }^{15}$ highlight the importance of understanding the stages of creativity and suggests that attributes of creativity are domain-general. These models are essential not only to how students learn but to how teachers teach. Having a deeper awareness of the person, process, press and product (Rhodes, 1961) of creativity, and how our curriculum can be shaped around it, can improve the readiness of students in an unpredictable future.

The group versus individual dichotomy is also key to the nurture of creativity in primary education, as it highlights the needs for educators to consider how each child is given the opportunity to develop themselves, but also work with others. Collaboration is key to the success of creative endeavours and can encourage students to become more engaged with their communities, making them better citizens.

\footnotetext{
12 RSA Animate (2010) Ken Robinson: Changing education paradigms, TED Talks.

13 Land, G. and Jarman, B., 1993. Breakpoint and beyond: Mastering the future-today. HarperCollins.

14 Rhodes, M. (1961) 'An analysis of creatvity', Phi Delta Kappan.

15 Runco, M. (2007) 'A hierarchical framework for the study of creativity', New Horizons in Education.
} 


\section{WHY IS CREATIVITY VITAL TO THE PRIMARY CURRICULUM?}

The nurture of creativity is a vital change that needs to occur in our primary schools. The Durham Commission (2019) suggests that, in England, we are failing in our ability to show children how to use their knowledge and that, in order to synthesise knowledge and creativity, we must use creativity itself. We should, throughout primary education, strive raise creative capital in young minds so that children can develop strong connections and longevity in learning. Kaufman and Beghetto (2009) believe creativity should be considered a learning goal and that creativity is one of the most important things we, as educators, can promote in young people.

Florida (2002) ${ }^{16}$ has described creativity as the most important economic resource of the 21st century, and as educators we are obliged to ensure that creative skills and attributes are developed fully. We must consider how to define creativity in the field of education, including whether it is specific to particular subjects or transferrable across all areas. Wiliam (2013) $)^{17}$ addresses the issue of creativity within his rigorous curriculum design principle, outlining the fact that it is not transferrable across subjects, but should be taught within each subject. The ability for students to understand how creative problem-solving is applicable but different in drama and maths, for example, demonstrates the level of rigor required of the curriculum. Although Wiliam talks about creativity lacking transferability if taught in only one domain, if it is addressed by teachers in all domains, then its transferability factor increases. Students are more likely to utilise their abilities of creative thinking if exposed to it more regularly, in all areas of learning. Curriculum design is vital to ensure that each subject area, be it English, Geography, Music or DT, has the space to develop creativity within it and demonstrate how factual and procedural knowledge intertwine, ultimately providing students with an advantage in an unpredictable, cross-domain future.

Guilford (1950) identified the need for increase awareness of creativity in education over 60 years ago, and the same level of urgency remains. This sentiment is echoed in a plethora of academic studies as well as business forums. The Durham Commission (2019) highlights the importance of creativity-centred learning in 'future-proofing' our young people so that they are prepared to face unpredictable futures in which their portfolio careers will see them work in a number of different fields. The World Economic Forum's Future of Jobs Report

16 Florida, R. (2002) 'The Rise of the Creative Class', Washington Monthly.

17 Wiliam, D., 2013. Principled curriculum design. SSAT (The Schools Network) Limited. 
$(2016)^{18}$ also states that communication, critical thinking, creativity and collaboration will be key desirable competences in business by 2022. These 'soft skills', as they are often termed, should form the very basis of primary education not only for the sake of children's futures, but for the sake of human development.

The Durham Commission on Creativity and Education (2019) defines teaching for creativity as 'explicitly using pedagogies and practices that cultivate creativity in young people', and there is a significant change that needs to take place to shift the culture of creative teaching and learning in the primary classroom in order to support effective development as well as to prepare children for life in the $21 \mathrm{st}$ century.

\section{CURRICULUM DESIGN AND PEDAGOGY}

A focus on curriculum design, as well as pedagogy and assessment, are vital to the implementation of creativity across all areas of learning. Pedagogy and curriculum work in synthesis together and should not be treated as separate entities, and the same stands for assessment; it is an essential tool to progression within the curriculum and enables appropriate learning to take place.

Curriculum design is a hot topic in education since changes made to the Ofsted inspection framework (2019), but are schools doing it correctly? Intention, implementation and impact are the buzzwords of the moment in curriculum leadership, but the consideration of curriculum design needs to go much further in order for so-called '21st century skills' to flourish alongside knowledge and experience.

Dylan Wiliam (2013) detailed the principles of curriculum design - balanced, rigorous, coherent, vertically integrated, appropriate, focused, relevant - that demonstrate the importance of close attention by all parties - leaders, teachers, parents, governors and students - to the way in which curricula are mapped out. The principles demonstrate another conflict within creativity. A curriculum would fail to achieve them all at the same level, at the same time, however they build upon the models of Tyler (2013) ${ }^{19}$ and Taba $(1962)^{20}$ in highlighting the need for leaders to develop a school's curriculum with clearly focused attention addressing the needs of learners and building on making connections between knowledge and skills through carefully considered content.

18 WEF (2016) The Future of Jobs, World Future Review.

19 Tyler, R. W. (2013) Basic Principles of Curriculum and Instruction, Basic Principles of Curriculum and Instruction. doi: 10.7208/chicago/9780226820323.001.0001.

20 Taba, H (1962) 'Curriculum development: Theory and practice'. New York, NY: Harcourt Brace Jovanowich. 
Ken Robinson (2010) ${ }^{21}$ talks about conformity as a hindrance to effective teaching of all minds and highlights the need to open children up to a range of experiences that engage all their senses, so that cultural and economic gaps are closed. Creativity plays an important role in this rebellion, and injecting it into the curriculum is a step in the right direction towards breaking down outdated approaches to learning. Initial 'revolutionary' approaches to education in the 18th and 19th centuries, which were appropriate to the economy and views of intelligence at that time, have not changed for our time. The conversation about suitability of curriculum design is more important than ever, as we struggle to understand what the future holds.

A damaging opinion of creative students is common among teachers due to the perceived lack of conformity, heightened impulsivity and disruptive behaviour. (Bereczki \& Kárpáti, 2018). ${ }^{22}$ The first step in addressing this is to engage teachers in their own creative development, providing opportunities to increase their own creative capital in order to understand how the creative process and its subprocesses (Boldt, 2019) ${ }^{23}$ positively contribute to learning. Creative pedagogies that enhance the learner's experience require the role of the teacher to become more hands-on and less rigid, encouraging multiple approaches to learning (Richardson and Mishra, 2018). ${ }^{24}$ Teachers should model how learning can take place away from traditional approaches, giving children time to explore and evaluate.

Bourdieu's 'cultural capital' $(1973)^{25}$ is a useful starting point from which to build creativity nurture. Extending his ideas into a sense of 'creative capital', the important exposure to culturally significant art, literature, activities, mannerisms, etc., grows into an exposure to the creative processes that created them, therefore raising the potential for all to be creatively successful, even in the smallest, most individual way. The work of Hirsch $(1987)^{26}$ on 'Cultural Literacy' addresses much of the same ideas of Bourdieu by outlining a list of essential information to

21 Robinson, K. (2010) Bring on the Learning Revolution. New York: TED Talk. https:// www.ted.com/talks/sir_ken_robinson_bring_on_the_learning_revolution (accessed 20th May 2020)

22 Bereczki, E. O. and Kárpáti, A. (2018) 'Teachers' beliefs about creativity and its nurture: A systematic review of the recent research literature', Educational Research Review. doi: 10.1016/j.edurev.2017.10.003.

23 Boldt, G. (2019) 'Artistic creativity beyond divergent thinking: Analysing sequences in creative subprocesses', Thinking Skills and Creativity. doi: 10.1016/j.tsc.2019.100606.

${ }^{24}$ Richardson, C. and Mishra, P. (2018) 'Learning environments that support student creativity: Developing the SCALE', Thinking Skills and Creativity. doi: 10.1016/j.tsc.2017.11.004.

25 Bourdieu, P., 1973. Cultural reproduction and social reproduction. London: Tavistock, 178.

${ }^{26}$ Hirsch, E. D. (1987) “"Cultural Literacy” Doesn't Mean “Core Curriculum”, The English Journal. doi: 10.2307/816894. 
support success. He believed that acquisition of this knowledge would close the gap between different demographic groups. This educational theory is important to consider when looking at curriculum design as it addresses the principle of balance (Wiliam, 2013) and ensures that students are given the opportunity to be equipped with all they need to know for their future. It focuses the emphasis of curricula on knowledge and the desire to place all learners on the same level, whatever their background.

The focus of knowledge in the curriculum is also addressed in Young's work on 'powerful knowledge' (2014). ${ }^{27}$ Young discusses the idea of two different types of knowledge, one being the 'better knowledge' available in every field, and the second being the knowledge that is brought to an experience; what the children brings of their own experience to the classroom. Knowledge is vital to the building of a creative curriculum because, as Csikszentmihalyi says, we must 'internalise the knowledge of the domain' in order that they become a part of everyday thinking, and then innovation (1997). Even the most influential creatives of human history started from acquiring knowledge of their field. Innovation has to innovate something. Creative curriculum design must have knowledge at the heart of it and be aware of progression within it; 'curriculum is a progression model', as Fordham $(2017)^{28}$ pointed out, and it should demonstrate a collaboration between knowledge and creative application of that knowledge.

The knowledge-based approach to curriculum links to the domain-specific versus general debate in the field of creativity research. In order to achieve significant level of creative achievement, we must be working within but sitting on the edges of a field (Csikszentmihalyi, 1996), indicating we need domainspecificity in creativity nurture. Curriculum design must consider how to endorse creative endeavours within every area of learning, as addressed above, so that the potential for these achievements is not stripped away. Failing that Big-C level of success, learners have still had their creativity abilities nurtured in order live a rich and fulfilling life, and 'a passion to live beyond death' (Wallace, 1986). The risks of a curriculum too focused on knowledge, however, are that teachers aim merely to fill children with facts, and the more they remember, the more successful the teaching. Freire's 'pedagogy of the oppressed' (follows a traditional theory of teacher-led instruction that omits any opportunity for creative learning through promotion of passivity in students. This theory demonstrates how the curriculum

\footnotetext{
27 Young, M. (2014) 'The curriculum and the entitlement to knowledge', Cambridge Assessment Network.

${ }^{28}$ Fordham, M (2020), 'What did I mean by 'the curriculum is the progression model'?' https://clioetcetera.com/category/knowledge-and-curriculum/.
} 
might look without any provision made for creativity and lacks merit in preparing students for the future.

Counsell (2018) ${ }^{29}$ supports the theory of providing students with specific knowledge of a discipline in order to renew and innovate it. Her work on curriculum leadership is centred around the idea that knowledge for individual subject areas must be mastered in order for creativity within it to flourish. By considering Counsell's view in curriculum design, a synthesis of creativity and knowledge is achieved. The Durham Commission report (Nelson, 2019) emphasised this need for amalgamation, as all creative products need a starting point.

\section{CONCLUSION}

A curriculum rich in creativity enables all individuals, artistically inclined or not, to engage with the creative process. For us human beings, creative processes are, and have been, integral to our evolution, progress and future. The richness that a creative process can give any aspect of our lives is invaluable, and it is this capital that will have significant impact on our futures. Creativity is a cross-disciplinary skill and should be found in all areas of the primary curriculum.

We are seeing a signification shift in the paradigms of education, with leaders having more autonomy over what is taught and teachers taking more control over how they're teaching. We are working in a time in which what has been the norm for so long is finally being challenged, and by ensuring that we equip educators with appropriate and applicable research we can support the movement towards relevant, rigorous and creative education that not only meets the needs of the learners, but enables them to flourish and shape our unpredictable future.

A curriculum that lacks creativity at its heart, including not only the content but the teacher-driven pedagogy and supportive, creative leadership, will not prepare young people for what lies ahead. As the Durham Commission (2019) states, the application of creative thought is necessary to thrive in a range of jobs and we are currently failing to demonstrate to students how knowledge can be used in creative ways and be a driver for change.

${ }^{29}$ Counsell, C (2018) 'In search of curriculum leadership' https://thedignityofthethingblog. wordpress.com/2018/03/27/in-search-of-senior-curriculum-leadership-introductiona-dangerous-absence. 